\title{
CORRESPONDENCE
}

The elusive orthopaedic senior house officer R Hole, FRCS; Helen Beaumont, $\mathrm{MB}$, and others.

Osteoporosis: cause and management

A W Fowler, FRCS; R Smith, FRCP; R $M$ Francis, MRCP, and P L Selby, MRCP; A R P Walker, DSC, and B F Walker, MD

When a woman asks for a caesarean section

J G Thornton, MRCOG, and R J Lilford, PHD...

Psychiatric disorder and gynaecological

symptoms in middle aged women

G Bell, MRCPSYCH and C Katona, MRCPSYCH;

D Gath, FRCPSYCH, and others
Acyclovir and pregnancy

B A L Hurn, MD, and Elizabeth Andrews, MPH

Oral acyclovir in acute herpes zoster

R J Marsh, FRCS, and M Cooper, BCHIR; M W McKendrick, MRCP, and others 703

F Wells, MRCGP

Primary pulmonary hypertension

T Higenbottam, MRCP, and J Wallwork, FRCS 70

HIV transmitted by kissing

703 J Seale, MRCP; C Monckton; L A Kay, MRCP
Death in the clouds

A K Marsden, FRCSED

Early emergency care

H J N Bethell, MRCP

704 Occult chlamydial ophthalmia in men with non-gonococcal urethritis

D Taylor-Robinson, FRCPATH; E F Monteiro,

MRCP, and others; J Mantell, MRCP, and B T

Goh, MRCP .................................... 706

Manpower

J Wardrope, fRCS .......................... 707

Because we receive many more letters than we have room to publish we may shorten those that we do publish to allow readers as wide a selection as possible. In particular, when we receive several letters on the same topic we reserve the right to abridge individual letters. Our usual policy is to reserve our correspondence columns for letters commenting on issues discussed recently (within six weeks) in the BMF.

Letters critical of a paper may be sent to the authors of the paper so that their reply may appear in the same issue.

We may also forward letters that we decide not to publish to the authors of the paper on which they comment.

Letters should not exceed $\mathbf{4 0 0}$ words and should be typed double spaced and signed by all authors, who should include their main degree.

The elusive orthopaedic senior house officer

SIR,-It seems certain that the shortage or orthopaedic senior house officers will be solved by the suggestion, approved by most of your correspondents (14 February, p 438), that orthopaedics be incorporated into the training programme for general practice. Unfortunately, shortages of applicants for junior medical posts are being noticed increasingly in other specialties, not all of which have up to now been considered to be unpopular. The scope for making the posts more attractive, by linking them to training schemes that at present attract large numbers of high quality applicants, must surely be limited. In addition, the inclusion of more hospital posts might lead to the training schemes themselves becoming less attractive and would certainly make unpopular posts outside those schemes even more difficult to fill.

Dr King is right: the service requirements of each specialty need to be assessed objectively, unencumbered by reference to the present staffing structure or method of remuneration. I suspect that the inquiry, would conclude that the unique hospital staffing arrangements of the Nationa Health Service are far less appropriate for all grades of doctors for the service requirement when compared with what is done (and how it is remunerated) in most other Western countries. No doubt no government could afford a change, but to assume now that no inquiry is necessary because the UK is the only country in step is foolish in the extreme.

ROGER HOLE

South Cleveland Hospital

Cleveland TS4 3BW

SIR,-We object to the widespread assumption that general practitioner trainees are available to fill junior posts that would otherwise be difficult to fill. Three letters (14 February, p 438) propose this naive solution to the problem of filling orthopaedic senior house officer posts, a suggestion which is an affront to the concept of general practitioner training. Mr J E Carvell explains that "The heightened clinical awareness of young doctors in general practitioner training helps to provide a very high standard of medical care in the orthopaedic wards and also serves to update and disseminate medical knowledge to the consultants." We do not doubt it. Do vocational trainees gain something equally worth while?

Many vocational trainees spend six months in an accident and emergency department, which is an ideal place to learn about acute orthopaedics. Certainly an additional senior house officer posting in orthopaedics would provide excellent experience in geriatrics and the use of the social services. Orthopaedics is not considered to be an essential job by the Joint Committee on Postgraduate Training for General Practice. As a group of vocational trainees who have all spent some time in general practice, we agree with this principle. If orthopaedic surgeons wish to recruit vocational trainees

\section{Osteoporosis: cause and management}

SIR,-DrRogerSmith states that the most common causes of osteoporosis are old age, immobility, and the menopause (7 February, p 329). As old age and the menopause are both physiological states they cannot be the cause of disease; they are markersthat is, clues that lead us to search for causes operating during these periods of life,

Though Dr Smith admits that the main way to establish maximal bone mass in early adult life is to exercise the skeleton, he fails to follow this reasoning to its logical conclusion, which is that continued exercise throughout life is the way to maintain bone mass and that osteoporosis related to age is an atrophy of bone caused by disease. Skeletal disuse is a component of all the common risk factors for osteoporosis-namely, old age, menopause, smok- they must prove the usefulness of cold orthopaedics to general practice.

Vocational training is not totally satisfactory, but compared with the general malaise of specialist training it has many merits. The hospital components of vocational training schemes are a political compromise between the requirements of training and the manpower situation. Posts selected for the two years of hospital employment should be shown to be relevant to general practice. We object to the plundering of our schemes by those who cannot sell their jobs on the open market.

Helen Beaumont JEREMY GRIMSHAW ANDREW LANGTON GABRIEL SHUSTER

National Conference of General Practitioner Trainees Working Party on Training, King's Lynn, Norfolk PE30 3RD

ing, alcoholism, anorexia nervosa, bedrest, and so on.

Surprisingly, Dr Smith makes no reference to the important demographic study by Chalmers and Ho, who, using femoral neck fractures as an index of osteoporosis, found that a reduction in physical activity was the most important factor and concluded that "a daily routine of physical activity may be as beneficial to the skeleton as it is recognised to be to the heart."' The paradoxical finding that osteoporosis may occur in women athletes and ballet dancers does not. invalidate the cardinal role of disuse in osteoporosis because such groups are indulging in a potentially harmful amount of exercise.

Why are we so reluctant to accept that in most 